\title{
COMITÊS DE EDUCAÇÃO INTEGRAL: MO(VI)MENTOS DOS/NOS DOCUMENTOS EDITADOS PELO MINISTÉRIO DA EDUCAÇÃO
}

\author{
JANAÍNA SPECHT DA SILVA MENEZES ${ }^{1}$ \\ ORCID: https://orcid.org/0000-0001-5839-7256 \\ CARLOS ANTÔNIO DINIZ JÚNIOR ${ }^{2}$ \\ ORCID: https://orcid.org/0000-0002-4420-3403
}

\begin{abstract}
RESUMO: O objetivo deste artigo é analisar os mo(vi)mentos associados à criação e implantação dos Comitês de Educação Integral, estabelecidos a partir do Programa Mais Educação. Alicerçado em referenciais teóricos que discutem a constituição de espaços de participação e controle social de políticas públicas e tendo por base a análise documental, o artigo examina os textos editados pelo governo federal, no período de 2007 a 2016, que tratavam desses comitês. Entre seus resultados, revela que a criação dos Comitês de Educação Integral buscou contribuir tanto com a consecução das ações vinculadas ao Mais Educação quanto com a construção e/ou consolidação de políticas locais de educação integral e(m) tempo integral, na perspectiva de que essas instâncias se constituíssem como espaços de exercício pedagógico para a vivência e o fortalecimento da democracia. Contudo, embora o trabalho identifique processos de ampliação da abrangência de atuação desses comitês no desenvolvimento de políticas de educação em tempo integral, revela que tais avanços não foram suficientes para firmar sua institucionalização em termos locais, a partir do ordenamento federal.
\end{abstract}

Palavras-chave: Comitês de Educação Integral, Programa Mais Educação, Participação e Controle Social.

\section{FULL-TIME EDUCATION COMMITTEES: MO(VE)MENTS FROM/IN THE DOCUMENTS EDITED BY THE MINISTRY OF EDUCATION}

\begin{abstract}
The purpose of this article is to analyze the mo(ve)ments associated with the creation and implementation of the Full-Time Education Committees, established from Mais Educação Program. Based on theoretical references that discuss the constitution of participation spaces and social control of public policies and based on document analysis, the article examines the texts edited by the federal government, from 2007 to 2016, which dealt with these committees. Among its results, it reveals that the creation of the Integral Education Committees sought to contribute both to the accomplishment of actions related to Mais Educação and to the construction and/or consolidation of local integral and fulltime education policies, in the perspective that these instances were constituted as spaces of pedagogical exercise for living and strengthening democracy. However, although the work indicates processes of
\end{abstract}

\footnotetext{
${ }^{1}$ Universidade Federal do Estado do Rio de Janeiro. Rio de Janeiro, RJ, Brasil. < janainamenezes@hotmail.com.br>

${ }^{2}$ Universidade Federal do Estado do Rio de Janeiro. Rio de Janeiro, RJ, Brasil. <junior.diniz.jd@gmail.com> Educação em Revista|Belo Horizonte|v.36|e230051|2020
} 
broadening the scope of these committees in the development of full-time education policies, it reveals that such advances were not enough to establish their institutionalization in local terms, based on the federal order.

Keywords: Full-Time Education Committees, Mais Educação Program, Participation and Social Control.

\section{COMITÉS DE EDUCACIÓN INTEGRAL: MO(VI)MIENTOS DE/EN LOS DOCUMENTOS EDITADOS POR EL MINISTERIO DE EDUCACIÓN}

RESÚMEN: El objetivo de este artículo es analizar los mo(vi)m(i)entos asociados con la creación e implantación de los Comités de Educación Integral, establecidos a partir del Programa Mais Educação. Basado en referencias teóricas que discuten la constitución de espacios para la participación y el control social de las políticas públicas y en base al análisis de documentos, el artículo examina los textos editados por el gobierno federal, de 2007 a 2016, que se ocupó de estos comités. Entre sus resultados, revela que la creación de los Comités de Educación Integral buscó contribuir con el cumplimiento de las acciones vinculadas al Programa Mais Educação y con la construcción y/o consolidación de políticas locales de educación integral y de jornada completa, en la perspectiva de que estas instancias se constituyeron como espacios de ejercicio pedagógico para la experiencia y el fortalecimiento de la democracia. Sin embargo, aunque el trabajo identifique procesos para ampliar el alcance de estos comités en el desarrollo de políticas educativas en jornada completa, revela que tales avances no fueron suficientes para establecer su institucionalización en términos locales, basados en el orden federal.

Palabras clave: Comités de Educación Integral, Programa Mais Educação, Participación y Control Social.

\section{INTRODUÇÃO}

A Constituição Federal de 1988 (BRASIL, 1988) marcou a retomada democrática no País, após a ditadura civil-militar (1964-1985), caracterizada, conforme apontado por Adrião e Camargo (2007), pela centralização e autoritarismo no/do funcionamento do Estado brasileiro. No tocante aos direitos sociais e individuais, entre outras determinações, a Constituição estabeleceu o direito à participação social e à democratização da gestão pública. Nesse sentido, segundo Bravo (2009), o princípio da participação e da representação popular asseverado pelo texto constitucional - em especial nos artigos 198 , 204 e 206 - aponta para a necessidade da participação e do controle social das políticas públicas no âmbito da saúde, assistência social e educação, nos três níveis de governo, como estratégia para a construção da democracia participativa. Assim, considerando tais questões, cabe ao Estado a constituição de espaços de participação e representação sob a égide do exercício do controle social das políticas públicas (ALVES; ALMEIDA, 2013). Tal pensamento vai ao encontro da reflexão de Pateman (1992), que aponta para o dever fundamental do Estado na constituição de espaços que, entre outros aspectos, se caracterizem pelo papel educativo da participação.

No contexto do Programa Mais Educação (PME) - instituído pela Portaria Interministerial $n^{\circ} 17 / 2007$ (BRASIL, 2007) e regulamentado pelo Decreto $n^{\circ} 7.083 / 2010$ (BRASIL, 2010) -, a busca pela participação se fez presente a partir de normatizações e materiais de apoio editados pelo Ministério da Educação (MEC) que, entre outras estratégias, propunham a criação de Comitês de Educação Integral, entendidos como instâncias de gestão do PME, bem como de fomento à constituição e/ou consolidação de políticas públicas locais de educação em tempo integral.

De acordo com documentos do PME, inicialmente os Comitês de Educação Integral tinham por objetivo integrar e articular diferentes atores sociais, setores - públicos e privados - e políticas sociais implicadas no programa (BRASIL, 2010a). Por sua vez, no decorrer da vigência do PME, os comitês passaram a ser compreendidos como instâncias consultivas e propositivas para o fomento e a articulação 
de ações, na perspectiva da gestão intersetorial, direcionadas para a construção de políticas de educação em tempo integral voltadas para a educação integral (BRASIL, 2016).

Para cumprir o objetivo a que se propõe - analisar os mo(vi)mentos associados à criação dos Comitês de Educação Integral, no âmbito do Programa Mais Educação -, este trabalho tomou por base de análise os textos que tratam dos referidos comitês, publicados durante a vigência do PME (20072016), a saber: os Manuais da Educação Integral (BRASIL, 2008; BRASIL, 2009; BRASIL, 2010a; BRASIL, 2011; BRASIL, 2012; BRASIL, 2013; BRASIL, 2014a); a Série Mais Educação - Gestão Intersetorial no Território (BRASIL, 2009a); a Nota Técnica nº 387/2015 (BRASIL, 2015); e a Portaria $\mathrm{n}^{\mathrm{o}}$ 12/2016 (BRASIL, 2016).

Partindo do exposto, este artigo, além da presente introdução, está constituído por outras quatro seções. A segunda, com base na revisão de literatura, discute a participação e o controle social no contexto das políticas públicas, destacando algumas instâncias instituídas para esse fim, como os conselhos, os fóruns e os comitês. A terceira apresenta os Comitês de Educação Integral, realçando o processo de ampliação da sua abrangência no território nacional que, inclusive, acabou por produzir alterações na sua nomenclatura no período pesquisado. Já a quarta seção apresenta o processo de busca por um ordenamento próprio para normatizar os comitês no âmbito nacional. Por fim, nas considerações finais, são abordados alguns dos principais resultados do estudo.

\section{POLÍTICAS PÚBLICAS, PARTICIPAÇÃO SOCIAL E CONTROLE SOCIAL}

Em cumprimento à Constituição Federal de 1988 e em consonância com a perspectiva da função educativa da participação para a "aquisição de habilidades e procedimentos democráticos" (PATEMAN, 1992, p. 60), o Estado brasileiro passou a desenvolver uma "participação institucionalizada" (AVRITZER, 2016, p. 14). Esse processo está marcado pela edição de leis infraconstitucionais que visam regulamentar a representação dos cidadãos em espaços de participação e controle social das políticas, no âmbito da União, estados, Distrito Federal e municípios. De tal modo, desde o início do processo de redemocratização, especialmente a partir da Constituição Federal de 1988, pôde-se observar o avanço crescente do número de instâncias - normatizadas - de participação social, seja, por exemplo, por meio da criação de conselhos de políticas sociais, como na educação, saúde e assistência; da realização de conferências nacionais; dos orçamentos participativos implementados em gestões locais; e/ou dos fóruns de debates e construção de políticas públicas (AVRITZER, 2016; FRATESCHI, 2016).

A institucionalização dessas instâncias - que devem ter a democracia como fundamento e o diálogo como método - implica a afirmação da sua importância para o fortalecimento da educação nacional enquanto espaços de interlocução entre a sociedade civil e o Estado brasileiro (MARINHO, 2017). Nesse sentido, diferentes estratégias vêm sendo empreendidas objetivando a busca pelo avanço da participação e controle social, a citar, os conselhos, os fóruns e os comitês. Assim, mesmo cientes da provisoriedade, incompletude e riscos de se buscar diferenciar essas três instâncias (ALVAREZ, 2004), para melhor execução e compreensão deste trabalho, ainda que de forma geral, faz-se necessário apresentar algumas de suas principais características.

Os conselhos, enquanto instância de participação e controle social, constituem-se em espaços voltados para a busca pela democratização do poder e da autoridade pública, estabelecendo-se como elo entre o Estado e a sociedade (CARNEIRO, 2002; CURY, 2002). Reforçam a lógica da participação social, do acompanhamento e do controle da sociedade civil em relação às ações do Estado, uma vez que a sociedade participa na elaboração e fiscalização das políticas públicas. No que tange aos fóruns, para Cortes e Gugliano (2010), essas instâncias, que também se constituem como espaços de participação e controle social, favorecem a construção de novas formas de "exercício coletivo do poder político" (p. 49). Sob essa perspectiva, são instituídas como espaços de discussão e acompanhamento de políticas públicas, gerais e/ou específicas, objetivando o estreitamento da relação entre o Estado e a sociedade civil (ABERS; JORGE, 2005; CORTES; GUGLIANO, 2010). Já os comitês de políticas públicas, também considerados como espaços de participação e controle social, são estratégias de 
"descentralização integrada e participativa" (ABERS; JORGE, 2005, p. 02) e são compostos por representantes do poder público, da sociedade civil e de usuários dessas políticas, organizados como espaços de deliberação. Tais instâncias possibilitam o acompanhamento, a implementação e o controle das políticas públicas setoriais, assumindo, inclusive, em alguns casos, responsabilidades associadas à sua execução.

Se, por um lado, essas três instâncias - conselhos, fóruns e comitês - podem ser identificadas como espaços de fortalecimento da relação entre o Estado e a sociedade civil, por outro, o processo de encolhimento do Estado, iniciado nos anos 1990, aponta para a transferência de responsabilidades para a sociedade civil (DAGNINO, 2004). Observa-se ainda que a própria compreensão de sociedade civil passou a ser ressignificada pela hegemonia do pensamento neoliberal, vinculado às ideias de diminuição do Estado. Se, anteriormente, o termo sociedade civil apresentava uma ideia ampla, associada aos cidadãos, de forma geral, hoje apresenta uma crescente associação ao terceiro setor e a fundações empresariais; enfim, aos organismos de hegemonia do capital (DAGNINO, 2004a; BATISTA, 2013).

Ainda no que tange aos conselhos, fóruns e comitês e, de modo mais geral, às instâncias de participação e controle social, é fundamental observar que todos são compostos por redes complexas de divergências de interesses que disputam lugares e poder (MÉSZÁROS, 2011). Além disso, cabe destacar, como apontam Cortes e Gugliano (2010), a vigilância e o controle exercido pelo Estado em relação à escolha dos membros que devem integrar tais instâncias, bem como a sua influência sobre as demandas a serem postas em discussão, que podem, por vezes, estar mais alinhadas a interesses particulares do que às reais necessidades da sociedade. Nesse sentido, tais instâncias, além de demandarem normatizações que regulamentem sua criação e funcionamento, contam ainda com processos de tensão e disputas internas.

\section{DO FÓRUM MAIS EDUCAÇÃO AOS COMITÊS DE EDUCAÇÃO INTEGRAL}

A Portaria Interministerial $n^{\circ} 17 / 2007$, ao instituir o PME, criou também o Fórum Mais Educação (BRASIL, 2007, Art. $9^{\circ}$ ), não tendo estabelecido qualquer referência aos Comitês de Educação Integral. Contudo, ao mesmo tempo que o Fórum Mais Educação nunca chegou a ser regulamentado, a presença dos Comitês de Educação Integral fez-se constante e crescente em todos os Manuais Operacionais de Educação Integral publicados pelo MEC na vigência do PME. Mais especificamente, embora o Fórum Mais Educação - que tinha como atribuição "coordenar a implementação" do PME (BRASIL, 2007, Art. $9^{\circ}$ ) -, por exemplo, tenha sido apresentado como um dos responsáveis pela elaboração do caderno "Programa Mais Educação: gestão intersetorial no território" (BRASIL, 2009a), e sua atuação potencial tenha sido mencionada em diferentes momentos no interior dessa publicação, ele nunca chegou a ser regulamentado, fato que contribuiu para impossibilitar sua efetiva constituição. Na lacuna da regulamentação do Fórum, a implementação do PME foi coordenada exclusivamente pelo MEC, tendo migrado da Secretaria de Educação Continuada, Alfabetização e Diversidade (Secad) para a Secretaria de Educação Básica (SEB).

A ausência de regulamentação do Fórum Mais Educação - que deveria ser constituído por "representantes dos Ministérios ou Secretarias Federais" que integrassem ou viessem a integrar o PME (BRASIL, 2007, Art. $9^{\circ}, \int 1^{\circ}$ ) - dificultou a consolidação, em âmbito federal, de um espaço intersetorial de discussão e acompanhamento das ações do programa, impondo obstáculos a um maior estreitamento das relações entre os ministérios e as secretarias envolvidas no PME, em prol de uma política educacional nacional de educação em tempo integral. Além disso, a não regulamentação do Fórum, entre outros aspectos, pode ter prejudicado o monitoramento e a avaliação do PME, haja vista que, entre suas atribuições, deveria "acompanhar a implementação do Programa gerando sua constante reavaliação, elaborando relatórios, pareceres e recomendações para seu aperfeiçoamento" (BRASIL, 2007, Art. 10, Inciso III). Assim, destaca-se aqui a importância de serem ultimados os processos de monitoramento e avaliação das políticas públicas, os quais, entre outros aspectos, oportunizam informações sobre a política em curso, a necessidade de (re)alocação de recursos e a verificação da legitimidade das ações e da necessidade de readequações (DERLIEN, 2001). 
Na contramão do que determinava a Portaria n 17/2007, o primeiro Manual de Educação Integral, editado em 2008 (BRASIL, 2008), além de não fazer qualquer menção ao Fórum Mais Educação, trouxe pela primeira vez à cena os Comitês de Educação Integral, os quais continuaram a constar em todos os manuais subsequentes, publicados anualmente até 2014 . Assim, considerando os objetivos do PME - que, dentre suas finalidades, a partir da ampliação da jornada escolar para o tempo integral, buscava contribuir para a melhoria da aprendizagem dos estudantes (BRASIL, 2010), bem como se constituir indutor da construção e/ou fortalecimento de políticas de educação em tempo integral junto às instâncias subnacionais (BRASIL, 2013a) -, o governo federal, por meio de manuais de apoio ao programa e de documentos específicos editados pelo MEC (BRASIL, 2008; BRASIL, 2009; BRASIL, 2010a; BRASIL, 2011; BRASIL, 2012; BRASIL, 2013; BRASIL, 2014a; BRASIL, 2015; BRASIL, 2016), propôs a constituição de Comitês de Educação Integral como espaços de gestão das atividades desenvolvidas pelo PME e de fomento à constituição e consolidação de políticas locais de educação em tempo integral. Tais comitês objetivam "articular e integrar os diferentes setores, atores e políticas sociais envolvidos com a implementação do Programa Mais Educação nas escolas e nas regiões onde ele está acontecendo" (BRASIL, 2010a, p. 17).

A partir da análise dos referidos documentos, é possível observar que, no decorrer da vigência do PME, ocorreu um expressivo avanço do envolvimento dos Comitês de Educação Integral com o Programa: se, em um primeiro momento, as ações dos comitês estiveram fortemente vinculadas ao acompanhamento e controle dos recursos do PME, na sequência, progressivamente, foram avançando não só na direção da implementação das ações do Programa, mas também das demais políticas de educação em tempo integral, desenvolvidas localmente. De forma gradual, foi-se consolidando a compreensão de que os Comitês de Educação Integral deveriam se constituir como "Instância[s] de gestão dos Programas de Educação Integral com objetivo de enraizar suas propostas e de ampliar a vivência de gestão compartilhada de políticas públicas educacionais e do regime de colaboração entre as secretarias e parceiros" (BRASIL, 2014, p. 39). Mais especificamente, tendo por base uma perspectiva intersetorial, os Comitês de Educação Integral passaram a ser configurados como espaços de gestão das atividades desenvolvidas pelo programa, assim como de fomento à constituição e consolidação de políticas públicas locais de educação em tempo integral.

Merece destaque uma importante característica - que acompanhou os documentos do PME e, por conseguinte, os Comitês de Educação Integral - da ação política desses comitês, qual seja, a intersetorialidade, cuja lógica da ação considera a "pobreza como fenômeno multidimensional" (BRONZO, 2010, p. 9) e cujo enfrentamento pressupõe a articulação das ações setoriais - saúde, educação, assistência social, entre outras -, a partir de uma nova maneira de planejar e executar as políticas públicas. Mais especificamente, a intersetorialidade parte de uma visão integradora dos problemas sociais para buscar superá-los (JUNQUEIRA, 2004).

Presente já na parte preliminar, a Portaria n 17/2007 considera que as políticas de "inclusão social e formação para a cidadania" apresentam caráter intersetorial e, sob essa perspectiva, devem trazer à corresponsabilidade todos os entes federados, destacando "a necessidade de planejamento territorial das ações intersetoriais, de modo a promover sua articulação no âmbito local” (BRASIL, 2007). O estímulo ao desenvolvimento de ações intersetoriais associadas ao PME e, em especial, aos Comitês de Educação Integral está presente já na constituição desses comitês - que deveriam contar com "um representante pedagógico para intersetorialidade" (BRASIL, 2008, p. 02; BRASIL, 2014, p. 39) - e avança para abarcar a busca pela "perspectiva intersetorial em sua dinâmica, visando tornar-se um amplo fórum de debates sobre a implementação e a execução de políticas públicas educacionais e sociais" (BRASIL, 2014, p. 39). Considera-se, assim, que as dinâmicas intersetoriais, instituídas no âmbito local, vão ao encontro do fortalecimento da autonomia da gestão, bem como daqueles sujeitos que elaboram e implementam políticas educacionais, uma vez que suas ações ocorrem na perspectiva da compreensão da necessária articulação da educação com as demais políticas sociais e com a vida dos indivíduos (ALMEIDA, 2014). À vista disso, no que tange à política federal de educação em tempo integral materializada por meio do Programa Mais Educação, percebe-se que a ação intersetorial, presente inicialmente no âmbito nacional a partir da possível implementação do Fórum Mais Educação, foi 
irradiada para o contexto subnacional, sendo que os Comitês de Educação Integral passaram a se constituir seus grandes bastiões.

A partir da análise dos documentos do PME editados pelo MEC, pode-se observar a presença simultânea de duas formas de organização dos Comitês de Educação Integral - locais e territoriais -, estabelecidas de acordo com o âmbito de atuação dessas instâncias de participação e controle social.

Os comitês locais deveriam ser constituídos no âmbito de cada unidade escolar que executava o PME. Integrados por professores, pais, representantes dos estudantes e da comunidade, deveriam desempenhar "o papel de instância permanente de debates acerca dos desafios e das possibilidades da educação integral” (BRASIL, 2014, p. 39). O MEC sugeria, inclusive, que cada um desses comitês fosse "coordenado por um colegiado" que deveria contemplar, entre seus integrantes, "um representante para execução financeira e prestação de contas da UEx" (BRASIL, 2014, p. 39). Tal recomendação se justifica pelo fato de a adesão ao PME ser seguida de um processo de descentralização de recursos financeiros - com origem no governo federal e operacionalizado por meio do Programa Dinheiro Direto na Escola (PDDE)/Educação Integral - para as escolas contempladas pelo programa. A formação do comitê local deveria se dar de forma articulada "com as demais instâncias participativas existentes na unidade escolar, em especial o Conselho Escolar", com vistas a "garantir a condução democrática e o controle social dos recursos públicos" (BRASIL, 2014, p. 34). Essa articulação poderia se constituir como uma contribuição para o fortalecimento local do controle social, de modo a se consolidar, tal qual apresentado por Calvi (2008), como uma das estratégias de participação organizada da sociedade civil na formulação, acompanhamento e fiscalização de políticas sociais e do Estado. Contudo, embora o MEC recomendasse a criação de comitês locais em todas as edições dos Manuais de Educação Integral, sua formação, conforme aconteceu com os comitês territoriais, não se constituiu condição para a adesão e/ou execução do PME por parte das escolas.

Com maior amplitude de atuação, os comitês territoriais, assim como os locais, tendo como referência o PME, também objetivavam contribuir para a qualificação da(s) política(s) pública(s) de educação em tempo integral voltada(s) para a educação integral, desenvolvida(s) em nível local. Sua criação deveria ser incentivada pelos coordenadores estaduais, distritais e municipais do Programa Mais Educação (BRASIL, 2014). De acordo com as orientações do governo federal, entre as atribuições desses coordenadores constavam "realizar a interface com a instância estadual e federal (SEB/MEC), fomentar e articular o Comitê Municipal, [...], elaborar e realizar ações de qualificação de atores e atividades das escolas, além de organizar e manter disponíveis os registros das ações” (BRASIL, 2014a, p. 34).

Voltados para o acompanhamento da execução das ações do PME, os comitês territoriais deveriam viabilizar a participação social com vistas a qualificar a gestão e a interlocução entre as políticas públicas, "na perspectiva de uma ação intersetorial" (BRASIL, 2014, p. 40). Nesse sentido, sua composição, além de abarcar a representação de cada secretaria de educação - estadual, distrital e municipal - que tivesse aderido ao PME no seu território de atividade, deveria integrar também "representantes de outras secretarias municipais, estaduais e distritais de áreas de atuação com interface no programa (Cultura, Esporte, Desenvolvimento Social e outras), universidades e atores sociais e institucionais diversos" que estivessem colaborando para a realização das ações do programa (BRASIL, 2014, p. 39). Ao articular a educação com outras instâncias governamentais, a intersetorialidade visava possibilitar "a constituição de um sistema estruturado em prol da educação" (MENEZES, 2012, p. 59), combinando experiências, saberes e recursos - humanos financeiros e materiais - dos setores envolvidos a favor de um objetivo educacional comum.

À medida que o PME foi se espraiando pelo território nacional, os comitês territoriais tiveram que empreender adaptações, haja vista que, progressivamente, foram agregando um maior número de municípios na sua composição. Afora alterações no seu modo de funcionamento, ocorreu um significativo movimento associado à tentativa de adequação de uma terminologia que expressasse o avanço da abrangência territorial de atuação desses comitês. Nesse sentido, se em um primeiro momento foram intitulados de "Comitês Metropolitanos" (BRASIL, 2008, 2009), posteriormente foram chamados de "Comitês Metropolitanos, Estaduais e Regionais" (BRASIL, 2010a, 2011), para, finalmente, receberem a denominação de "Comitês Territoriais" (BRASIL, 2012, 2013, 2014a). 
O quadro 1, ao apresentar como os comitês eram mencionados nos Manuais de Educação Integral, auxilia na compreensão de que os mo(vi)mentos vinculados a tal terminologia decorreram, entre outros aspectos, conforme apresentado por Diniz Júnior (2017), do processo de capilarização do PME no território nacional, bem como de pressões originadas no âmbito dos próprios comitês que apontavam para a necessidade dessas mudanças.

Quadro 1 - Comitês de Educação Integral - 2008-2016

\begin{tabular}{|c|c|}
\hline Ano & Denominações dos Comitês nos Manuais de Educação Integral \\
\hline 2008 & \multirow{2}{*}{$\begin{array}{l}\text { - Comitês Locais } \\
\text { - Comitês Metropolitanos }\end{array}$} \\
\hline 2009 & \\
\hline 2010 & \multirow{2}{*}{$\begin{array}{ll}\text { - } & \text { Comitês Locais } \\
\text { - } & \text { Comitês Metropolitanos, Estaduais e Regionais }\end{array}$} \\
\hline 2011 & \\
\hline 2012 & \multirow{5}{*}{$\begin{array}{l}\text { - Comitês Locais } \\
\text { - Comitês Territoriais }\end{array}$} \\
\hline 2013 & \\
\hline 2014 & \\
\hline $2015^{(*)}$ & \\
\hline $2016^{(*)}$ & \\
\hline
\end{tabular}

Fonte: Elaborado com base em Brasil (2008; 2009; 2010a; 2011; 2012; 2013 e 2014a).

(*) Embora o MEC não tivesse editado novos Manuais nos anos de 2015 e 2016, orientou que as instâncias subnacionais seguissem as disposições do Manual de 2014.

Nos dois primeiros anos de vigência, o PME teve sua atuação focalizada nas capitais e cidades das regiões metropolitanas com "mais de 200.000 habitantes" (BRASIL, 2008, p. 30) e "mais de 100 mil habitantes" (BRASIL, 2009, p. 01), fato que levou à associação da denominação dos comitês ao âmbito estrito dessas regiões, fazendo com que, a partir de então, tivessem sido intitulados "Comitês Metropolitanos".

Além disso, no decorrer da sua vigência, o PME buscou avançar com a focalização de suas ações em grupos sociais vulneráveis (MENEZES; PAIVA; OLIVEIRA, 2018). Assim, tendo em vista que "a condição de vulnerabilidade de um cidadão se manifesta na proporção inversa da proteção a ele oferecida pelo Estado" (SILVA, 2018, p. 41), um dos principais direcionamentos do PME consistiu na conjugação do "binômio educação e assistência social [entendida] como fator decisivo na promoção da cidadania e da garantia de direitos" (SILVA, 2018, p. 84). Observa-se ainda que a focalização em grupos sociais vulneráveis, presente no PME, também está em consonância com as orientações de documentos editados por organismos internacionais (UNESCO, 1990; CEPAL; UNESCO, 1996; BANCO MUNDIAL, 1999) que apontam para a priorização do atendimento desses grupos por parte das políticas educacionais públicas.

A atenção a grupos sociais vulneráveis implicou, entre outros aspectos, a progressiva redefinição dos critérios de contagem populacional para a localização das escolas que poderiam aderir ao programa, uma vez que tal condição se estende para além dos limites das regiões metropolitanas. Assim, em 2010 e 2011, passaram a poder aderir ao programa as escolas localizadas, respectivamente, em cidades com "mais de 90 mil habitantes" (BRASIL, 2010a, p. 09) e "superior a 18.844 habitantes" (BRASIL, 2011, p. 07), fato que fez com que o PME deixasse de atender exclusivamente as áreas metropolitanas para se expandir para outros territórios. Nessa ocasião, os comitês passaram a ser intitulados "Comitês Metropolitanos, Estaduais e Regionais".

A partir do ano de 2012, a contagem populacional deixou de estar presente entre os critérios para adesão ao PME, emergindo, por conseguinte, uma nova nomenclatura associada aos comitês, qual seja, Comitês Territoriais. Além disso, considera-se que a alteração da denominação decorreu do alinhamento à valorização e ao reconhecimento do território como elemento educador, presente no Movimento Cidades Educadoras, que, segundo Cavaliere (2014), também estava presente nas concepções pedagógicas do PME. 
Tal alteração de nomenclatura decorreu também da influência das experiências práticas vivenciadas pelas diferentes organizações dos Comitês de Educação Integral presentes no País. Mais especificamente, de acordo com pesquisa realizada por Diniz Júnior (2017), essa mudança deveu-se à necessidade de não se vincular a denominação "estadual" a um determinado comitê, uma vez que sua utilização possibilitava a intepretação de que a Secretaria de Estado de Educação seria a responsável por sua estrutura e funcionamento. Nesse sentido, segundo o autor, a estratégia adotada para o enfrentamento dessa questão foi a alteração da nomenclatura de "estadual" para "territorial", que buscou mitigar a centralidade da referida secretaria, contribuindo para o entendimento de que os comitês de educação integral deveriam se constituir como espaços horizontalizados de discussão.

Cabe destacar que, buscando consolidar as ações da política indutora de educação em tempo integral no País, expressa pelo PME, no período de 2009 a 2014, não só o MEC realizou alguns seminários associados ao Programa, como, a partir de seus comitês, também o fizeram alguns estados e municípios, em parceria ou não com o Ministério (OLIVEIRA, 2014). Tais eventos buscaram se configurar, também, como espaços de (re)definição da política e, por conseguinte, de (re)organização dos próprios Comitês de Educação Integral.

\section{COMITÊS DE EDUCAÇÃO INTEGRAL: A BUSCA POR UM ORDENAMENTO PRÓPRIO}

Tendo como possível estratégia a conquista de um ordenamento normativo próprio, os Comitês de Educação Integral buscaram avançar no seu processo de institucionalização. Sob essa perspectiva, foram elaboradas a Nota Técnica no 387/2015 (BRASIL, 2015) e a Portaria n 12/2016 (BRASIL, 2016), que correspondem aos dois únicos documentos editados pelo MEC, na vigência do PME, associados exclusivamente aos Comitês de Educação Integral, os quais, vale observar, tratam apenas dos comitês territoriais, não havendo qualquer menção aos comitês locais. De acordo com Diniz Júnior (2017), a edição desses dois documentos resultou não só da compreensão da importância dos Comitês de Educação Integral para o avanço da qualidade da educação básica, como também de demanda encaminhada pelos comitês territoriais à SEB/MEC.

Ao editar a Nota Técnica $n^{\circ} 387 / 2015$, o MEC reconheceu, do ponto de vista administrativo, os Comitês Territoriais de Educação Integral como uma "Estratégia de Política Pública de Educação Integral, para promover a Educação Básica Pública de Qualidade a todos os cidadãos" (BRASIL, 2015, p. 3), sendo que a associação da ampliação da jornada escolar ao avanço da qualidade em educação acompanhou toda a trajetória do PME. Estudos de Cavaliere (2014) revelam que o programa alinha a ampliação da jornada escolar e a mobilização da sociedade como estratégias para a melhoria da qualidade da educação, ideia também presente no Plano de Desenvolvimento da Educação (PDE).

Além disso, a preocupação com o desempenho dos estudantes, aferido através da Prova Brasil3 e sistematizado pelo Índice de Desenvolvimento da Educação (IDEB), constituiu-se como critério de adesão das escolas ao PME durante toda a sua vigência, como pode ser observado nos Manuais da Educação Integral (BRASIL, 2008; BRASIL, 2009; BRASIL, 2010a; BRASIL, 2011; BRASIL, 2012; BRASIL, 2013; BRASIL, 2014a), reforçando, assim, a ideia da associação do tempo integral a possíveis avanços da qualidade em educação, no caso, aferida por avaliações e indicadores em larga escala. Contudo, por se constituir como estratégia indutora da educação em tempo integral junto a estados e municípios, a trajetória do PME resulta matizada e modificada por essas instâncias de governo (CAVALIERE, 2014), que podem decidir por desenvolver uma concepção de escola de tempo integral balizada por sua própria noção de qualidade, para além daquela estabelecida em nível federal. Observase, ainda, que a autora conjuga direito e qualidade na educação ao afirmar que: "O direito à educação traduz-se hoje, no Brasil, como o direito a um padrão de qualidade educacional, em que pesem as

\footnotetext{
${ }^{3}$ O Sistema de Avaliação da Educação Básica (Saeb) foi reformulado pela Portaria Ministerial no $931 / 2005$, passando a ser composto por duas estratégias de avaliação: a Avaliação Nacional de Rendimento Escolar (Anresc), também conhecida como Prova Brasil, e a Avaliação Nacional da Educação Básica (Aneb) (OLIVEIRA, 2011). Educação em Revista|Belo Horizonte|v.36|e230051|2020
} 
dificuldades em estabelecer-se um consenso sobre a própria noção de qualidade" (CAVALIERE, 2014, p. 1206).

Ainda no que tange à Nota Técnica no 387/2015, estudos de Diniz Júnior (2017) revelam que ela foi editada como resultado da pressão exercida pelos comitês territoriais instalados no País, demonstrando, em certa medida, que esses coletivos, à época, exerciam um papel de influência nas decisões do Ministério. Para o autor, o advocacy 4 realizado pelos referidos comitês, associado à elaboração de um documento exclusivo emanado do governo federal, deveu-se, especialmente, à necessidade de os membros dessas instâncias se sentirem amparados para reivindicar a regulamentação dos comitês locais de educação integral. Tal normatização se fazia necessária, entre outros aspectos, para que os membros desses comitês pudessem ter sua participação operacionalizada e legitimada em meio, não raro, às frequentes trocas de gestores à frente das secretarias de educação do País.

A análise da Nota Técnica $n^{\circ} 387 / 2015$ e da Portaria nº 12/2016 demonstra que esses documentos não apresentam diferenças significativas de conteúdo, que, em parte, já constava nos manuais operacionais do PME. Partindo dessa informação, vale destacar a inclusão da Fundação Joaquim Nabuco 5 (Fundaj), ao lado da Diretoria de Currículos e Educação Integral/Dicei/SEB/MEC, na condição de instância que deveria "fomentar o processo de instituição dos comitês territoriais de educação integral nos territórios em que eles não se constituíram por iniciativa local", cabendo-lhes também o dever de promover seu fortalecimento por meio "de uma rede colaborativa de comitês territoriais de Educação integral” (BRASIL, 2016, Art. 2, Parágrafo único). Sendo assim, nesses documentos, a constituição do Fórum Mais Educação parece ter sido definitivamente substituída pela parceria entre a SEB/MEC e a Fundaj, fundação que, à época, sediava o Comitê Territorial de Educação Integral de Pernambuco. Sob essa nova perspectiva, a relação da Fundaj com a SEB/MEC passou a ultrapassar os limites da ação do próprio Comitê de Pernambuco, para se firmar como uma parceria em ações relacionadas ao fortalecimento dos comitês territoriais, bem como do próprio PME.

Observa-se que tanto a nota técnica quanto a portaria reconhecem os comitês como "coletivos democráticos" com responsabilidades em relação às políticas educacionais:

Assim a DICEI/SEB/MEC reconhece a importância dos Comitês como espaço coletivo democrático para a discussão de políticas educacionais locais, assumindo desafios na construção de uma nova realidade que envolva corresponsabilidade e interação com o processo educacional nos territórios (BRASIL, 2015, p.1).

A reflexão sobre os comitês remete à ideia de sujeitos coletivos ou sociais que, segundo Merhy (1993), se caracterizam e se aproximam em decorrência de suas pautas de reivindicação e de seus interesses. Pode-se compreender então que os comitês se constituem não apenas como um espaço de articulação para a garantia da política, mas especialmente de defesa da educação em tempo integral voltada para a educação integral. Essa compreensão vai ao encontro da ideia dos comitês com papel de advocacy em favor da educação integral, como já mencionado anteriormente.

É importante ressaltar que a Portaria no 12 foi editada no dia 11 de maio de 2016, um dia após o Senado ter votado a abertura do processo de impeachment contra a presidente Dilma Rousseff. Esse destaque faz-se necessário para salientar o momento político presente no País e a crise institucional acarretada por aquele processo, que se desdobrou em insegurança e descontinuidade das ações em curso. Além disso, a elaboração dos dois documentos associados exclusivamente aos comitês territoriais enfrentou dificuldades junto ao ministro de educação da época, que parecia não reconhecer a importância do PME e, por conseguinte, dos Comitês de Educação Integral, apontando, inclusive, para uma possível descontinuidade ou reorganização do Programa no contexto educacional brasileiro. As declarações do referido ministro sobre a necessidade de reorganização do PME foram amplamente divulgadas nos meios de comunicação e se fizeram associar diretamente à necessidade de priorização no aprendizado da Língua

\footnotetext{
4 Advocacy é a ação de lobby, em favor de um tema a ser institucionalizado ou que se pleiteia institucionalização (SILVA, 2007).

${ }^{5}$ Criada por meio da Lei no $6.687 / 1979$ como autarquia vinculada ao MEC, a Fundaj articula hoje, juntamente com outros setores, o Comitê Territorial de Políticas Públicas de Educação Integral em Pernambuco. Nos anos de 2013 e 2014, organizou a "I e II Escola de Comitês de Educação Integral" (FUNDAJ, 2014). 
Portuguesa e Matemática no contexto da ampliação da jornada escolar, no caso, no âmbito do PME (EBC, 2015; REVISTA EXAME, 2015).

Em meio a um cenário político adverso, a referida portaria acabou por não ser assinada pelo então ministro da educação, mas pelo secretário de educação básica do MEC. Sob essa perspectiva, convém observar que, de acordo com Silva (2013), portaria é um ato editado pelo Executivo ou por quem a lei autorizar, constituindo-se como um ato de regulação que, para que se converta em força de lei, precisa ser regulamentada por decreto ou lei, o que, no caso dos Comitês, não chegou a ocorrer. Sendo assim, considera-se que tanto a nota técnica quanto a portaria se consolidaram como instrumentos de reconhecimento, e não de efetiva institucionalização dos Comitês de Educação Integral no território nacional.

Em 2016, o PME foi substituído pelo Programa Novo Mais Educação, cujos principais documentos orientadores - Portaria n 1.144/2016 (BRASIL, 2016a); Resolução n 17/2017 (BRASIL, 2017) e o Caderno de Orientações Pedagógicas (BRASIL 2018) - não fizeram menção aos Comitês de Educação Integral, fato que, infelizmente, não surpreende, haja vista, segundo Dourado (2007), que as políticas educacionais no Brasil apresentam como traço hegemônico a lógica da descontinuidade.

\section{CONSIDERAÇÕES FINAIS}

As instâncias de participação e controle social - a citar os conselhos, os fóruns e os comitês - têm sua instituição alicerçada, entre outros aspectos, no entendimento de que o Estado democrático de direito apresenta como pilar fundamental a democracia participativa. Tal entendimento advém da compreensão de que a participação política dos cidadãos deve se estender para além do voto naqueles que deverão representá-los junto aos poderes Executivo e Legislativo para abarcar também um maior envolvimento com a gestão pública, incluindo a possibilidade de fiscalizar tanto as atividades daqueles que foram eleitos pelo voto popular quanto acompanhar e controlar as políticas públicas implementadas nos âmbitos nacional e/ou local.

Sob essa perspectiva, ao estabelecer uma maior aproximação entre a sociedade civil e o governo, os Comitês de Educação Integral, estabelecidos a partir do PME, além de se constituírem em ferramenta estratégica para o fortalecimento da democracia, buscam contribuir para o avanço da garantia do direito à educação em tempo integral, que, espera-se, seja desenvolvida sob a perspectiva da educação integral. De forma mais específica, além de contribuírem com a execução das ações associadas ao PME, bem como com a construção e/ou consolidação de políticas locais de educação integral e(m) tempo integral, os Comitês de Educação Integral estabelecem-se como espaços de exercício pedagógico para a vivência e o fortalecimento da democracia.

Constituídos em dois níveis - local e territorial -, a abrangência de atuação desses últimos comitês foi sendo ampliada à medida que o PME passou a conquistar maior capilaridade no território nacional, fato que contribuiu para que, progressivamente, recebessem diferentes nomenclaturas associadas ao avanço da abrangência da sua dimensão territorial, quais sejam, Comitês Metropolitanos; Comitês Metropolitanos, Estaduais e Regionais; e, por fim, Comitês Territoriais.

Nos sete primeiros anos de vigência do PME, tanto o tratamento dos Comitês de Educação Integral quanto a recomendação de sua criação por parte das instâncias subnacionais estiveram associadas exclusivamente às edições dos Manuais de Educação Integral (BRASIL, 2008; BRASIL, 2009; BRASIL, 2010a; BRASIL, 2011; BRASIL, 2012; BRASIL, 2013; BRASIL, 2014a). Nos anos seguintes, o MEC editou dois documentos - Nota Técnica no 387/2015 e Portaria no 12/2016 - voltados para os comitês territoriais, remetendo, assim, à compreensão da importância dos Comitês de Educação Integral para o desenvolvimento de políticas de educação em tempo integral, haja vista sua potencial interface com o avanço da qualidade da educação básica. Contudo, em razão da categoria normativa e teor, tais documentos acabaram por se constituir predominantemente como instrumentos de reconhecimento da importância dessas instâncias de participação e controle social por parte do governo federal, e menos como de efetiva institucionalização desses Comitês. 
Por fim, ao trazer à cena educacional os Comitês de Educação Integral, percebidos como instâncias singulares de participação e acompanhamento social das políticas de educação em tempo integral, busca-se trazer à discussão a necessidade de serem fortalecidos os processos que envolvem sua institucionalização - que têm no ordenamento normativo importante alicerce, devendo, contudo, ultrapassá-lo -, entendida como necessária, porém não suficiente, para o fortalecimento das ações desses comitês, especialmente em países que carecem avançar no fortalecimento da democracia.

\section{REFERÊNCIAS}

ABERS, Rebecca; JORGE, Karina D. Descentralização da Gestão da Água: Por que os comitês de bacia estão sendo criados? Revista Ambiente \& Sociedade - Vol. VIII nº. 2 jul./dez. 2005.

ADRIÃO, Thereza; CAMARGO, Rubens B. A gestão democrática na Constituição Federal de 1988. In.: OLIVEIRA, R. e ADRIÂO, T. Gestão, financiamento e Direito à Educação. São Paulo: Xamã, 3ed. 2007.

ALMEIDA, Ney L. T. de. Descentralização e Intersetorialidade: desafios para a consolidação da Política Pública de Educação. In.: MONNERAT, Giselle L.; ALMEIDA, Ney L. T. de; SOUZA, Rosimary G. de. A intersetorialidade na agenda das políticas sociais. Campinas, SP: Papel Social, 2014.

ALVAREZ, M.C. Controle Social: notas em torno de uma noção polêmica. Revista: São Paulo em Perspectiva, 18(1): 168-176, 2004.

ALVES, Jolinda M.; ALMEIDA, Denise M. F. Participação e controle social: as experiências do Conselho Municipal de Assistência Social de Londrina/PR. Revista: O Social em questão. RJ: Ano XVII, no 30, 2013.

ASSOCIAÇÃO INTERNACIONAL DE CIDADES EDUCADORAS (AICE). Educação e vida urbana: 20 anos das Cidades Educadoras. 2008. Disponível em: http://www.edcities.org/wpcontent/uploads/2015/11/livro-20-anos-cidades-educadoras-PT.pdf. Acesso em: 26 mar. 2018.

AVRITZER, Leonardo. Impasses da Democracia no Brasil. Rio de Janeiro: Civilização Brasileira, 2016.

BANCO MUNDIAL. Education Sector Strategy. Washington, D.C., World Bank, 1999.

BATISTA, Neusa C. Políticas públicas para a Gestão Democrática da Educação Básica: um estudo do Programa Nacional de Formação de Conselheiros Municipais de Educação. Jundiaí, SP: Paco Editorial, 2013.

BRASIL. Constituição Federal de 1988. Brasília: Senado Federal, 1988.

BRASIL. Lei no 10.172, de 09 de janeiro de 2001. Aprova o Plano Nacional de Educação - PNE e dá outras providências. Brasília, 2001.

BRASIL. Manual de Redação Parlamentar e Legislativa, editado pelo Senado Federal. 2006. Disponível em: http://www2.senado.leg.br/bdsf/item/id/70466. Acesso em: 18 mar. 2019.

BRASIL. Portaria Normativa Interministerial no 17, de 24 de abril de 2007. Institui o Programa Mais Educação, que visa fomentar a educação integral de crianças, adolescentes e jovens, por meio do 
apoio a atividades socioeducativas no contraturno escolar. Diário Oficial da União, Brasília, DF, 26 abr. 2007.

BRASIL. Secretaria de Educação Básica. Diretoria de Currículo e Educação Integral. Manual Operacional da Educação Integral, no exercício de 2008. Brasília, 2008.

BRASIL. Secretaria de Educação Básica. Diretoria de Currículo e Educação Integral. Manual Operacional da Educação Integral, no exercício de 2009. Brasília, 2009.

BRASIL. Gestão Intersetorial no Território. Brasília: MEC, SECAD, 2009a.

BRASIL. Educação integral: texto referência para o debate nacional. Brasília: MEC, SECAD, 2009b.

BRASIL. Secretaria de Educação Básica. Diretoria de Currículo e Educação Integral. Redes de Saberes: Mais Educação - Pressupostos para projetos pedagógicos de educação integral. Brasília, 2009c.

BRASIL. Decreto n ${ }^{\circ}$ 7.083, de 27 de janeiro de 2010. Dispõe sobre o Programa Mais Educação. Diário Oficial da União, Brasília, DF, 27 jan. 2010.

BRASIL. Secretaria de Educação Básica. Diretoria de Currículo e Educação Integral. Manual Operacional da Educação Integral, no exercício de 2010. Brasília, 2010a.

BRASIL. Secretaria de Educação Básica. Diretoria de Currículo e Educação Integral. Manual Operacional da Educação Integral, no exercício de 2011. Brasília, 2011.

BRASIL. Secretaria de Educação Básica. Diretoria de Currículo e Educação Integral. Manual Operacional da Educação Integral, no exercício de 2012. Brasília, 2012.

BRASIL. Secretaria de Educação Básica. Diretoria de Currículo e Educação Integral. Manual Operacional da Educação Integral, no exercício de 2013. Brasília, 2013.

BRASIL. Programa Mais Educação: Impactos na educação integral e integrada (Relatório de pesquisa). Brasília, MEC, 2013a. Disponível em: http://educacaointegral.mec.gov.br/biblioteca. Acesso em: 04 maio 2019.

BRASIL. Lei no 13.005, de 25 de julho de 2014. Aprova o Plano Nacional de Educação - PNE e dá outras providências. Brasília, 2014.

BRASIL. Diretoria de Currículo e Educação Integral. Manual Operacional da Educação Integral, no exercício de 2014. Brasília, 2014a.

BRASIL. Nota Técnica n 387, de 16 de outubro de 2015. Apresenta informações sobre os Comitês Territoriais de Educação Integral - Ação Intersetorial. 2015.

BRASIL. Portaria no 12, de 11 de maio de 2016. Dispõe sobre os Comitês Territoriais de Educação Integral e dá outras providências. Diário Oficial da União, Brasília, DF, 12 mai. 2016.

BRASIL. Portaria n 1.144, de 10 de outubro de 2016a. Institui o Programa Novo Mais Educação, que visa melhorar a aprendizagem em língua portuguesa e matemática no ensino fundamental. Diário Oficial da União, Brasília, DF, 11 out. 2016a. 
BRASIL. Resolução ${ }^{\circ}$ 17, de 22 de dezembro DE 2017. Destina recursos financeiros, nos moldes operacionais e regulamentares do Programa Dinheiro Direto na Escola - PDDE, a escolas públicas municipais, estaduais e do Distrito Federal, a fim de contribuir para que estas realizem atividades complementares de acompanhamento pedagógico, em conformidade com o Programa Novo Mais Educação. Diário Oficial da União, Brasília, DF, 26 dez. 2017.

BRASIL. Programa Novo Mais Educação caderno de orientações pedagógicas versão II. Disponível em: http:/ / portal.mec.gov.br/index.php?option $=$ com_docman\&view $=$ download\&alias $=70831$-pnmecaderno-de-orientacoes-pedagogicas-pdf\&category_slug=agosto-2017-pdf\&Itemid=30192. Acesso em: 13 maio 2019.

BRASIL. Escola deve criar unidade executora para receber recursos. Disponível em: http://portal.mec.gov.br/ultimas-noticias/214296700251/13118-escola-deve-criar-unidade-executora-para-receberrecursos. Acesso em: 30 mar. 2019.

BRAVO, Maria I. S. O trabalho do assistente social nas instâncias públicas de controle democrático. In: CFESS-ABEPSS. Serviço Social: direitos sociais e competências profissionais. Unidade IV: O significado do trabalho do assistente social nos distintos espaços sócio-ocupacionais. Brasília: Cfess/Abepss, 2009.

BRONZO, Carla. Intersetorialidade, autonomia e território em programas municipais de enfretamento da pobreza: experiências de Belo Horizonte e São Paulo. Planejamento e Políticas Públicas, n. 35, jul-dez, 2010.

CALVI, Kéttini U. O Controle Social nos Conselhos de Políticas e de direitos. Revista Emancipação, Ponta grossa, v.8, n.1, 09-20, jan/jun, 2008.

CARNEIRO, Carla B. L. Conselhos de políticas públicas: desafios para sua institucionalização. Revista de Administração Pública, Rio de Janeiro 36(2):277-92, Mar./Abr. 2002.

CAVALIERE, Ana Maria. Escola pública de tempo integral no Brasil: filantropia ou política de Estado? Educação \& Sociedade, v. 35, n. 129, p. 1205-1222, 2014.

CEPAL-UNESCO. Educacíon y conocimineto: eje de la transformacíon productiva con equidade. UNESCO, 1996.

CORTES, Soraia V.; GUGLIANO, Alfredo. Entre neocorporativistas e deliberativos: uma interpretação sobre os paradigmas de análise dos fóruns participativos no Brasil. Sociologias, Porto Alegre, ano 12, n. 24, p. 44-75, mai./ago. 2010.

CURY, Carlos R. J. Gestão Democrática da Educação: exigências e desafios. RBPAE. Jul/dez, 2002.

DAGNINO, E. Confluência perversa, deslocamentos de sentido, crise discursiva. In.: GRIMSON, A. La cultura en las crisis latino-americanas. Clacso, Buenos Aires. 2004.

DAGNINO, E. Sociedade civil, participação e cidadania: de que estamos falando. Políticas de ciudadanía y sociedad civil en tiempos de globalización. Caracas: FACES, Universidad Central de Venezuela, p. 95-110, 2004a. 
DERLIEN, Hans-Ulrich. Una comparación internacional em la evaluación de las políticas públicas. Revista do Serviço Público, ano 52, n.1, jan./mar., 2001.

DINIZ JÚNIOR, Carlos Antônio. Comitês Territoriais de Educação Integral: das ideias ao texto. Dissertação (Mestrado em Educação). Programa de Pós-graduação em Educação. Universidade Federal do Estado do Rio de Janeiro, Rio de Janeiro, 2017.

DOURADO, LUIZ Fernandes. Políticas e gestão da Educação Básica no Brasil: limites e perspectivas. In: Revista Educação e Sociedade. Campinas. vol. 28, n.100 - Especial, p. 921 - 946, out. 2007.

EBC. Mais Educação: Mercadante quer melhorar o aprendizado de português e matemática. 2015. Disponível em: http://agenciabrasil.ebc.com.br/educacao/noticia/2015-10/mais-educacaomercadante-quer-melhorar-o-aprendizado-de-portugues-e. Acesso em: 30 mar. 2019.

EXAME. Prioridade de Mercadante é rever o Programa Mais Educação. 2015. Disponível em: https://exame.abril.com.br/brasil/mercadante-quer-rever-programa-mais-educacao/. Acesso em: 01 abr. 2019.

FUNDAJ. Formação Continuada da Escola de Comitês de Educação Integral. Disponível em: https://www.fundaj.gov.br/index.php/area-de-imprensa/3941-educacaoglauce. Acesso em: 30 abr. 2019.

FUNDAJ. II Escola de Comitês de Educação Integral do Brasil. Disponível em: https://www.fundaj.gov.br/index.php/area-de-imprensa/3983-comitesterritoriais. Acesso em: 30 abr. 2019.

FRATESCHI, Yara. Participação social institucionalizada para a democratização da democracia. Dois Pontos, v. 13, n. 2, 2016.

JUNQUEIRA, Luciano A. P. A gestão intersetorial das políticas sociais e o terceiro setor. Saúde e Sociedade v.13, n.1, jan-abr, 2004.

MARINHO. André. O Fórum Nacional de Educação: processos (des)instituintes. Dissertação (Mestrado em Educação). Programa de Pós-Graduação em Educação. Universidade Federal do Estado do Rio de Janeiro, Rio de Janeiro, 2017.

MENEZES, Janaina Specht da Silva; PAIVA, Flávia Russo; OLIVEIRA, Luana Gomes de. O Programa Mais Educação e a construção da política pública de educação em tempo integral em Mesquita/RJ. In: Ana Emília Gonçalves de Castro; Ana Lúcia Hazin Alencar; Cibele Maria Lima Rodrigues; Cleide de Fátima Galiza de Oliveira. (Orgs.). Educação em tempo integral: ampliação de tempos, espaços e horizontes. 1ed.Recife: Editora UFPE, 2018, v. 01, p. 107-135.

MENEZES, Janaina Specht da Silva. Educação em tempo integral: direito e financiamento. Educar em Revista (Impresso), no 45, jul./set., p. 137-152, 2012.

MERHY, E. E. Planejamento ascendente: será que os municípios têm algo a dizer sobre isso, para a montagem do SUS? Saúde em debate. n. 39. 1993.

MÉSZÁROS, István. Para Além do capital: Rumo a uma teoria da transição. SP: Boitempo. 2011. O'DONNELL, Guillermo. Apuntes para una teoría del Estado. Revista Mexicana de Sociología, p. 1157-1199, 1978. 
OLIVEIRA, Luana Gomes. A formação continuada no âmbito do Programa Mais Educação no município de Mesquita - RJ. Dissertação (Mestrado em Educação). Programa de Pós-graduação em Educação. Universidade Federal do Estado do Rio de Janeiro, Rio de Janeiro, 2014.

OLIVEIRA. A. P. M. A Provra Brasil como uma política de regulação da rede pública do Distrito Federal. Dissertação (Mestrado em Educação). Programa de Pós-graduação em Educação Universidade de Brasília. Brasília, 2011.

PATEMAN, Carole. Participação e Teoria Democrática. Rio de Janeiro: Paz e Terra. 1992. SILVA, Luiz M. Sociedade, esfera pública e agendamento. In: LAGO, C.; BENETTI, M. Metodologia de pesquisa em jornalismo. Porto Alegre: Vozes, 2007.

SILVA, Margareth Correa. Educação integral e proteção social no contexto de uma escola pública de tempo integral. Dissertação (Mestrado em Educação). Programa de Pós-graduação em Educação. Universidade Federal do Estado do Rio de Janeiro, Rio de Janeiro, 2018.

UNESCO. Declaração Mundial sobre Educação para Todos: satisfação das necessidades básicas de aprendizagem. UNESCO: Jomtien, 1990.

Submetido: $17 / 10 / 2019$

Aprovado: $21 / 08 / 2020$ 